\title{
Effects of Pyruvate Supplementation on High- intensity Interval Exercise Induced Metabolic Acidosis and Repeated Sprint Exercise Performance of College Soccer Athletes
}

\section{yanping yang}

Beijing Sport University https://orcid.org/0000-0002-2271-1896

Junqiang Qiu ( $\sim$ qiujq001@sina.com )

Beijing Sport University https://orcid.org/0000-0001-8313-9216

Mengyue Wang

Beijing Sport University School of Sports Science

\section{Lin Feng}

Beijing Sport University

Dan Luo

Beijing Sport University

Ruirui Gao

Beijing Sport University

\section{Research article}

Keywords: Exercise induced metabolic acidosis, High-intensity interval exercise, Energy metabolism, Exercise performance, Sodium pyruvate

Posted Date: March 31st, 2021

DOl: https://doi.org/10.21203/rs.3.rs-371005/v1

License: (c) (1) This work is licensed under a Creative Commons Attribution 4.0 International License. Read Full License 


\section{Abstract}

Background. The effects of pyruvate on metabolic acidosis and oxidative metabolism had been studied. The ability to attenuate acidosis and improve oxidative system contribution are critical to the performance of team sport athletes during perform multiple high-intensity exercise over a limited period of time. This study aimed to investigate the impact of pyruvate supplementation on energy metabolism and metabolic acidosis during high-intensity interval exercise (HIIE), as well as to evaluate its role on repeated sprint exercise (RSE) performance.

Methods: 14 well-trained male college soccer athletes (age: $20 \pm 2$ years, body fat: $13.11 \pm 3.50 \%$ ) were studied in a randomized, double-blind, cross-over study. The participants ingested either $0.1 \mathrm{~g} / \mathrm{kg} / \mathrm{d}$ of pyruvate or a placebo for 1-week. Metabolic acidosis was induced by HIIE after the supplement period, and RSE ability in the acidosis state was assessed. Venous blood $\mathrm{pH}$, bicarbonate $\left(\mathrm{HCO}_{3}{ }^{-}\right)$and base excess (BE) were measured at baseline, pre-HIIE, post-HIIE, pre-RSE and post-RSE. Finger-stick blood lactate were collected at baseline, immediately after each bout of HIIE and 3, 5, 7, 10 min after HIIE. The energy systems contribution during HIIE were estimated.

Results. $\mathrm{Blood} \mathrm{pH}, \mathrm{HCO}_{3}{ }^{-}$and $\mathrm{BE}$ were significantly lower than baseline after $\mathrm{HIIE}(p<0.01)$ in both pyruvate group (PYR) and placebo group (PLA). Compared to $\mathrm{PLA}$, the blood $\mathrm{pH}, \mathrm{HCO}_{3}{ }^{-}$and $\mathrm{BE}$ were significantly improved in PYR at pre-HIIE $(p<0.01)$, post-HIIE $(p<0.01)$ and pre-RSE $(p<0.01)$.

Furthermore, blood BE remained higher in PYR than PLA till end of RSE $(p<0.05)$. The contribution of oxidative system in the fourth bout of HIIE was higher in PYR than PLA $(p<0.05)$. In PLA, the ratio of total anaerobic energy contribution during HIIE was higher than that of aerobic (oxidative) $(p<0.01)$, but not in PYR $(p>0.05)$. Relative peak power (RPP) of first, fifth sprint, relative average power (RAP) of fifth sprint, the average of RPP and RAP during RSE were significantly improved in PYR compared with PLA ( $p<$ $0.05)$. While no significant changes in the PD\% of each bout $(p>0.05)$ or average PD\% $(p>0.05)$ were observed between the two groups.

Conclusion: Pyruvate supplementation for 1-week enhances oxidative system energy contribution and buffers metabolic acidosis during HIIE, and improves RSE performance in acidosis.

\section{Introduction}

Most team sports involve number of high-intensity exercise and sprints with limited recovery interval ${ }^{1,2}$. During high-intensity exercise, the exercise intensity/ATP requirement is too high for $\mathrm{H}^{+}$to be used in mitochondrial respiration, exacerbating hydrogen ion $\left(\mathrm{H}^{+}\right)$synthesis ${ }^{3}$. Meanwhile, $\mathrm{H}^{+}$produced by skeletal muscle is co-transported with lactate to the blood, where $\mathrm{H}^{+}$is buffered by bicarbonate $\left(\mathrm{HCO}_{3}{ }^{-}\right)^{4}$. As energy requirements of exercise reach the maximal $\mathrm{H}^{+}$buffering ability, elevated $\mathrm{H}^{+}$reduces the $\mathrm{pH}$ of blood and muscle, leading to intracellular and extracellular metabolic acidosis ${ }^{3}$. The $\mathrm{pH}$ in skeletal muscles can even drop below $6.5^{5,6,7,8}$ with the blood lactate $>5 \mathrm{mM}, \mathrm{pH}<7.35, \mathrm{HCO}_{3}{ }^{-}<20 \mathrm{mM}$ and 
base excess $(\mathrm{BE})<-2 \mathrm{mM}^{9}, 10$. Although the influence of metabolic acidosis on exercise performance are controversial ${ }^{11}, 12,13,14$, accumulation of $\mathrm{H}^{+}$in skeletal muscle may impair muscle contraction and exercise efficiency ${ }^{15}$.

Repeated sprint exercise (RSE) is commonly considered as an important scenario of competitive sports, despite the fact that sprint-type activities only account around $10 \%$ of the total distance of team sports ${ }^{16}$. Team sport performance is affecting by RSE fatigue factors, which including insufficient creatine phosphate $\left(\mathrm{PCr}\right.$ ) resynthesis and intramuscular $\mathrm{H}^{+}$accumulation ${ }^{6,17}$. Reducing metabolic acidosis and increasing the potential of oxidative system to re-synthesize PCr will be of great benefit to exercise performance for team sport athletes.

Typical alkaline buffers can attenuate extracellular acidosis by acting as a physical and chemical buffer $18,19,20$. Pyruvate, on the other hand, can be transferred into cells as an intracellular buffer to attenuate metabolic acidosis ${ }^{21}$. In addition, since pyruvate has a low dissociation constant ( $\mathrm{pKa}=$ $2.49)^{22}$, it mainly relies on regulating intracellular metabolism to prevent metabolic acidosis ${ }^{23}$. Studies have shown that pyruvate is a key intermediate of glucose and a natural inhibitor of pyruvate dehydrogenase kinase (PDK) ${ }^{24}$. Pyruvate supplementation is thought to play roles in reducing pyruvate dehydrogenase $(\mathrm{PDH})$ phosphorylation and improving $\mathrm{PDH}$ activity ${ }^{25}$, and therefore promoting oxidative system metabolism and generating more energy and $\mathrm{HCO}_{3}{ }^{-26,27,28}$. There are reports that supplement with $0.1 \mathrm{~g} / \mathrm{kg} / \mathrm{d}$ pyruvate for 60 min could increase blood $\mathrm{pH}, \mathrm{HCO}_{3}{ }^{-}$and $\mathrm{BE}$ in the resting state of healthy individuals, and its buffer effect lasts for $120 \mathrm{~min}^{29}$. Whilst others have observed that acute pyruvate supplementation has little effect on high-intensity exercise induced metabolic acidosis caused ${ }^{30}$.

Sodium pyruvate is a non-toxic substance. The oral maximum lethal dosage is $10000 \mathrm{mg} / \mathrm{kg}$ body weight. Pyruvate injections of $600 \mathrm{mg} / \mathrm{kg}$ were shown to be safe in a 30-day toxicity trial. Supplementing of $0.5-1.0 \mathrm{~g} / \mathrm{kg} / \mathrm{d}$ for over a year is harmless or has no side effects in human ${ }^{2,29}$.

To our knowledge, few studies have documented the effects of pyruvate supplement on team sport exercise induced metabolic acidosis and exercise performance. This study evaluated the effects of pyruvate on metabolic acidosis and team sport performance from the perspective of energy metabolism. We hypothesized that pyruvate ingestion contributed to energy availability and environmental alkalization during RSE, leading to better performance.

\section{Methods}

\section{Subjects}

15 college male soccer athletes volunteered to participate into this study. Exclusion criteria included: hypertension, diabetes, cardiovascular risk factors, other any diagnosed diseases, smoking, ingested alcohol, caffeine, nutritional supplements and drugs one week before and throughout the study. Inclusion 
criteria: 1) 18-24 year; 2) BMI ranged from 18.5 to $23.9 \mathrm{~kg} / \mathrm{m}^{2}$; 3) At least 5 years of regular soccer training experience, maximal oxygen uptake over $50 \mathrm{ml} / \mathrm{kg} / \mathrm{min}$. The study protocol was approved by the Internal Review Board of Beijing Sport University (2020057H). All subjects were informed the aims of the study and were asked to sign an informed consent. One participant dropped out after graded cycling exercise test. 14 athletes completed all the sessions and were included in the data analyses (Table 1).

Table 1

Participant characteristics

\begin{tabular}{|c|c|c|c|c|c|c|}
\hline $\begin{array}{l}\text { Age } \\
\text { (year) }\end{array}$ & Height $(\mathrm{cm})$ & $\begin{array}{l}\text { Weight } \\
(\mathrm{kg})\end{array}$ & $\begin{array}{l}\text { Body fat } \\
(\%)\end{array}$ & $\mathrm{VO}_{2 \max }$ & $\mathrm{W}_{\max }$ & $\begin{array}{l}\text { Training year } \\
\text { (year) }\end{array}$ \\
\hline $20 \pm 2$ & $\begin{array}{l}178.31 \pm \\
6.36\end{array}$ & $\begin{array}{l}69.58 \pm \\
7.22\end{array}$ & $\begin{array}{l}13.11 \pm \\
3.50\end{array}$ & $\begin{array}{l}55.93 \pm \\
5.36\end{array}$ & $\begin{array}{l}298.54 \pm \\
41.7\end{array}$ & $9 \pm 3$ \\
\hline
\end{tabular}

\section{Study design}

A randomized, double-blind, crossover designed trials was used in this research. There were five laboratory visits, each divided by 7 days. The first visit involved personal information collection, body composition measurement, familiarization with exercise test protocol and performed a graded cycling exercise test (GXT). Second visit, they measured body composition and took sodium pyruvate or maltodextrin $(0.1 \mathrm{~g} / \mathrm{kg} / \mathrm{d})$ for 7 days (parallelly and randomly, PYR $(n=7), \operatorname{PLA}(n=7))$. During the third visit, 45-min after the last supplementation, the subjects took a 15-minute resting oxygen uptake test $\left(\mathrm{RO}_{2}\right)$. Then performed high-intensity interval exercise (HIIE) test to induce metabolic acidosis, and conducted RSE capacity test 10 min after HIIE. Subjects had third round of body composition measurement at fourth visit, those who supplied pyruvate/maltodextrin in the first round were switched to maltodextrin/pyruvate (parallelly and randomly, PYR $(n=7)$, PLA $(n=7)$ ). After 1-week, they returned to the laboratory and replicated the test they had done during the third visit. Each subject performed the tests at the same time of day and the same laboratory environment.

Participants arrived in a resting and thoroughly hydrated condition of $\geq 2 \mathrm{~h}$ post-prandial, avoid any strenuous exercise and carbonated drinks, alcohol, caffeine $24 \mathrm{~h}$ before each exercise test. A 3-day dietary recall was used to measure calorie intake and macronutrient consumption ( 2 weekdays and 1 weekend). Subjects took a 24-hour recall to measure dietary consumption the day before the first trial, and were asked to replicate the same diet as accurately as possible in subsequent studies. To ensure compliance, participants were expected to ingest the supplement under supervision. Fig. 1 presents a timeline for this study.

\section{Body composition measurements}


Height was collected to the nearest $0.1 \mathrm{~cm}$ using a calibrated electronic scale (GMCS-SGJ3, Jianmin, Beijing, China). Body composition was assessed $2 \mathrm{~h}$ after meal by multi-frequency bioelectrical impedance measurements device (Inbody 230, Biospace, Seoul, Korea).

\section{Graded cycling exercise test}

Each subject performed GXT on an electromagnetically braked cycle ergometer custo-med EC 3000e (custo med, Ottobrunn, Germany) to determine peak power ( $\left.\mathrm{W}_{\max }\right)$ and maximum oxygen uptake. Participants adjusted the seat and warmed up for 3 min at 50W. Then, pedal frequency was kept between 75 to $80 \mathrm{rpm}$, with load increased at $30 \mathrm{~W}$ per minutes. The standards for exhaustion included: 1) Subjects failed to keep 75rpm for $5 \mathrm{~s}$, voluntary exhaustion; 2) Increase the power load, but $\mathrm{VO}_{2}$ change $\leq$ $150 \mathrm{ml} / \mathrm{kg} / \mathrm{min} ; 3)$ Respiratory exchange rate $\left.\left(\mathrm{VCO}_{2} / \mathrm{VO}_{2}\right) \geq 1.10 ; 4\right)$ Heart rate reached 220 -age. $\mathrm{VO}_{2 \text { peak }}$ is the average oxygen consumption $30 \mathrm{~s}$ before reaching exhaustion ${ }^{31}$. $\mathrm{W}_{\text {max }}$ was calculated as the power of the last completed stage plus the fraction of time spent in the final non-completed stage multiplied by $30 \mathrm{~W}^{32,33}$. The rate of perceived exertion (RPE) and heart rate (HR) were measured during the test using the Borg scale (6-20) ${ }^{34}$ and Polar V800 (Polar Electro Oy, Oulu, Finland).

\section{Supplementation protocol}

Sodium pyruvate (Lianlu industrial Co., Ltd., Shanghai, China) and maltodextrin were randomly packed in capsule A or B that similar in appearance, size and weight. Each participant took $0.1 \mathrm{~g} / \mathrm{kg} / \mathrm{d}^{35}$ pyruvate or maltodextrin for 7 days (ingested 2 capsules per meal and 1 capsule before sleep for the first 6 days; supplied 60 min prior to exercise test for the 7 th day ${ }^{35}$ ). Subjects took capsule $A$ this time were switched to capsule $B$ the next time.

\section{Oxygen uptake test}

$\mathrm{VO}_{2}$ was measured breath-by-breath at CXT, rest, during HIIE and 10 min after HIIE using a portable gas analyzer (Cortex Metamax 3B, CORTEX Biophysik, Leipzig, Germany).

$\mathrm{RO}_{2}$ was measured 45-min after last supplementation. Participants take a 15-min break in a sitting position. The $\mathrm{RO}_{2}$ was determined using the average of the last 10 min of data collected ${ }^{36}$.

The gas analyzer was calibrated pre-exercise in accordance with the instructions of manufacturer.

\section{HIIE protocol}


HIIE was conducted in an electromagnetically braked cycle (Ergoline Ergoselect 100K, Ergoline, Bitz, Germany). During the test, subjects took a warm-up at $60 \mathrm{~W}$ for 5 min. HIIE consisted of 4 * 1 min cycling bouts at $110 \% \mathrm{~W}_{\text {max }}$. Cadence was constant (90-100 rpm) and were interspersed by $1 \mathrm{~min}$ rest intervals. Volunteers remained seated on the ergometer to took a 10-min break after finishing the last bout.

\section{RSE test}

RSE consisted 6 * $6 \mathrm{~s}$ of all out maximal cycling was performed on a mechanically braked cycle ergometer (Monark Ergomedic 894E, Monark, Vansbro, Sweden). Exercise load = weight $(\mathrm{kg}) \times$ $0.087 \mathrm{kp} / \mathrm{kg}$ (weight) ${ }^{37}$. During the test, participants adjusted the seat and began to fully ride when the staff countdown "3, 2, 1, start". Once cadence reached $110 \mathrm{rpm}$, the load of ergometers inertial was adjusted to the predetermined load. Subjects keep fully pedaling to complete $6 \mathrm{~s}$ cycling exercise, encouragement was provided to enable subjects to exert maximum ability. Each sprint with $24 \mathrm{~s}$ rest interval $^{38}$.

RPP: the highest power output (PP) relative to body mass observed in each $6 \mathrm{~s}$; RAP: the average power output (AP) relative to body mass maintained in each $6 \mathrm{~s}$; Power drop (PD\%): the percent of decay of mechanical power during the entire test with respect to peak power, according to the following equation: $P D \%=[(P P-A P) / P P \times 100]$. All the parameters were calculated via Monark Anaerobic Testing software (Version: 3.3.0.0, Developed in Co-operation with HUR Labs).

\section{Blood collection and analyses}

10 ul of finger-stick capillary blood samples were collected (wiped away the first drop of blood) in a Biosen capillary tube (EKF Diagnostics, Barleben, Germany) at baseline, end of each $110 \% \mathrm{VO}_{2 \text { max }}$ bout, 3 , 5, 7, 10 min after HIIE and post-RSE. The samples were analyzed using lactate analyzer (Biosen C-Line, EKF Diagnostics, Barleben, Germany) to measure blood lactate concentration.

$1 \mathrm{ml}$ of blood samples were obtained from ulnar vein at baseline, pre-HIIE, post-HIIE, pre-RSE and postRSE. The samples were collected in sodium heparin tube and immediately assessed blood $\mathrm{pH}, \mathrm{HCO}_{3}{ }^{-}, \mathrm{BE}$ by blood gas analyzer (Radiometer ABL80, FLEX CO-OX, Willich, Germany).

\section{Estimation of energy contribution}

Oxygen uptake: resting oxygen consumption was subtracted from the oxygen consumption obtained during each $110 \% \mathrm{~W}_{\max }$ bout. Oxidative energy system contribution = total oxygen uptake $(\mathrm{L}) \times 20.92 \mathrm{~kJ}$ 39 . 
Lactate difference before and after each $110 \% \mathrm{VO}_{2 \max }$ bout assumed to calculate glycolytic energy contribution. $1 \mathrm{mM}$ of lactate corresponds to $3 \mathrm{ml}$ of oxygen $/ \mathrm{kg}$ of body mass ${ }^{39}$.

Phosphagen energy system contains two sections. First, resting oxygen uptake was subtracted from the oxygen consumption obtained during each 1-min interval. In addition, fast component of excess postexercise oxygen uptake (EPOC fast) accessed during 6 min of HIIE recovery was adjusted by a biexponential model (OriginPro 8.0, OriginLab, Microcal, Massachusetts, USA). EPOC fast was assumed as the product of the amplitude and time constant of the first exponential model ${ }^{40}$.

\section{Statistical analyses}

A power analysis (Power 1- $\beta=0.9$ and $\alpha=0.05$ ) was performed a priori in $G *$ Power software version 3.1.9.6 (Universitat Kiel, Germany), 12 participants were needed for the present study. Data analyzed were carried out using SPSS, version 22.0. (SPSS Inc. Chicago, IL, USA). The Shapiro-Wilk test was used to verify the assumptions of normality of the data. Non-parametric Kruskal-Wallis test was used to analyze power drop (\%). Two-way repeated measures ANOVA was performed to assess the interaction between time (baseline, each bout of HIIE and each sprint of RSE) and the cohort (PYR and PLA). Simple effect analysis was performed for the horizontal comparison of between-group-factors when there was an interaction. Longitudinal comparison of within-group-factors was performed when there was no interaction. Independent samples t-tests were used to measure total, relative energy contribution during HIIE and average PD\% during RSE. Values were expressed as mean \pm SD or median (P25, P75). The statistical significance level was set at $p<0.05$.

\section{Results}

All subjects were supplemented with pyruvate or placebo as required under the supervision of staff. No subjects reported any side effects related to the supplementation, and there was no significant treatment order effect in the study. Subjects maintained exercise and dietary habits before each testing visit according to nutritional and exercise guidelines.

\section{Exercise induced metabolic acidosis}

There was no significant difference for blood $\mathrm{pH}, \mathrm{HCO}_{3}{ }^{-}, \mathrm{BE}$ and lactate at baseline. Blood pH $(p<0.01)$, $\mathrm{HCO}_{3}{ }^{-}(p<0.01), \mathrm{BE}(p<0.01)$ significantly decreased, lactate significantly increased at post-HIIE than baseline. Metabolic acidosis was remained till RSE finished. Blood $\mathrm{pH}, \mathrm{HCO}_{3}{ }^{-}$and $\mathrm{BE}$ were significant improved in PYR than PLA at pre-HIIE $(p<0.01)$, post-HIIE $(p<0.05)$ and pre-RSE $(p<0.05)$, Moreover, blood BE in PYR was higher than PLA till post-RSE $(p<0.05)($ Table 2$)$. 
Table 2

Blood $\mathrm{pH}, \mathrm{HCO}_{3}{ }^{-}, \mathrm{BE}$ and lactate for each group

\begin{tabular}{|c|c|c|c|c|c|c|}
\hline & Group & Baseline & pre-HIIE & post-HIIE & pre-RSE & post-RSE \\
\hline \multirow[t]{2}{*}{ Blood pH } & PYR & $\begin{array}{l}7.38 \pm \\
0.04\end{array}$ & $\begin{array}{l}7.40 \pm \\
0.03^{\star \star}\end{array}$ & $\begin{array}{l}7.20 \pm \\
0.05^{\star} \triangle \triangle\end{array}$ & $\begin{array}{l}7.24 \pm \\
0.06^{\star} \triangle \triangle\end{array}$ & $\begin{array}{l}7.23 \pm \\
0.07 \triangle \triangle\end{array}$ \\
\hline & PLA & $\begin{array}{l}7.36 \pm \\
0.03\end{array}$ & $7.37 \pm 0.03$ & $\begin{array}{l}7.14 \pm \\
0.08 \triangle \triangle\end{array}$ & $\begin{array}{l}7.17 \pm \\
0.09 \triangle \triangle\end{array}$ & $\begin{array}{l}7.18 \pm \\
0.07 \triangle \triangle\end{array}$ \\
\hline \multirow[t]{2}{*}{$\begin{array}{l}\text { Blood } \mathrm{HCO}_{3}{ }^{-} \\
(\mathrm{mmol} / \mathrm{L})\end{array}$} & PYR & $\begin{array}{l}24.55 \pm \\
1.15\end{array}$ & $\begin{array}{l}26.09 \pm \\
0.82 \star \star \triangle \triangle\end{array}$ & $\begin{array}{l}14.56 \pm \\
1.83 * \triangle \triangle\end{array}$ & $\begin{array}{l}15.24 \pm \\
2.10 * \triangle \triangle\end{array}$ & $\begin{array}{l}14.04 \pm \\
2.32 \triangle \triangle\end{array}$ \\
\hline & PLA & $\begin{array}{l}24.52 \pm \\
0.96\end{array}$ & $24.86 \pm 1.03$ & $\begin{array}{l}12.57 \pm \\
1.86 \triangle \triangle\end{array}$ & $\begin{array}{l}13.02 \pm \\
2.05 \triangle \triangle\end{array}$ & $\begin{array}{l}12.52 \pm \\
1.61 \triangle \Delta\end{array}$ \\
\hline \multirow[t]{2}{*}{$\begin{array}{l}\text { Blood BE } \\
(\mathrm{mmol} / \mathrm{L})\end{array}$} & PYR & $\begin{array}{l}1.06 \pm \\
1.15\end{array}$ & $\begin{array}{l}3.39 \pm \\
0.86^{\star \star \Delta \triangle} \Delta\end{array}$ & $\begin{array}{l}-12.58 \pm \\
3.24^{\star} \triangle \triangle\end{array}$ & $\begin{array}{l}-11.68 \pm \\
3.49 \star \Delta \triangle\end{array}$ & $\begin{array}{l}-13.64 \pm \\
3.50 \star \Delta \triangle\end{array}$ \\
\hline & PLA & $\begin{array}{l}1.16 \pm \\
1.30\end{array}$ & $2.00 \pm 1.11$ & $\begin{array}{l}-15.61 \pm \\
4.39 \triangle \triangle\end{array}$ & $\begin{array}{l}-14.98 \pm \\
4.37 \triangle \triangle\end{array}$ & $\begin{array}{l}-16.56 \pm \\
3.07 \triangle \triangle\end{array}$ \\
\hline \multirow[t]{2}{*}{$\begin{array}{l}\text { Blood lactate } \\
(\mathrm{mmol} / \mathrm{L})\end{array}$} & PYR & $\begin{array}{l}2.23 \pm \\
0.61\end{array}$ & $1.69 \pm 0.44$ & $\begin{array}{l}13.58 \pm \\
3.63 \triangle \triangle\end{array}$ & $\begin{array}{l}12.80 \pm \\
2.76 \triangle \triangle\end{array}$ & $\begin{array}{l}14.24 \pm \\
2.81 \triangle \triangle\end{array}$ \\
\hline & PLA & $\begin{array}{l}2.40 \pm \\
0.68\end{array}$ & $2.09 \pm 0.59$ & $\begin{array}{l}14.23 \pm \\
2.56 \triangle \triangle\end{array}$ & $\begin{array}{l}13.42 \pm \\
2.52 \triangle \triangle\end{array}$ & $\begin{array}{l}14.70 \pm \\
2.26 \triangle \triangle\end{array}$ \\
\hline
\end{tabular}

\section{Energy contribution}

Compared to bout 1 , there were significant increase of absolute oxidative energy system contribution ( $p<$ 0.01 ), while, the absolute glycolytic energy system contribution showed a significant decrease throughout bouts in both groups $(p<0.05)$. The oxidative energy system contribution of the fourth $110 \% \mathrm{VO}_{2 \max }$ bouts was significantly improved in PYR than PLA $(p<0.05)$. Whereas the contribution of glycolytic and phosphagen energy systems were not significant changed during four bouts of high-intensity exercise (Table 3). The ratio of total anaerobic energy contribution during HIIE was higher than that of aerobic (oxidative) energy in PLA ( $p<0.01)$, but not in PYR (Fig. 2). 
Table 3

Energy contribution during HIIE for each group

\begin{tabular}{|c|c|c|c|c|c|c|c|}
\hline Energy system & Group & Bout 1 & Bout 2 & Bout 3 & $\begin{array}{l}\text { Bout 4/ } \\
\text { EPOC fast }\end{array}$ & Total & $\begin{array}{l}\text { Relative } \\
\text { contribution } \\
\text { (\%) }\end{array}$ \\
\hline \multirow[t]{2}{*}{$\begin{array}{l}\text { Oxidative } \\
\text { system (kJ) }\end{array}$} & PYR & $\begin{array}{l}43.19 \\
\pm 6.50\end{array}$ & $\begin{array}{l}50.75 \pm \\
7.06^{\# \#}\end{array}$ & $\begin{array}{l}55.48 \pm \\
6.52^{\# \#}\end{array}$ & $\begin{array}{l}59.14 \pm \\
7.07^{\star \# \#}\end{array}$ & $\begin{array}{l}202.64 \\
\pm 18.08\end{array}$ & $49.47 \pm 1.77$ \\
\hline & PLA & $\begin{array}{l}43.33 \\
\pm 9.00\end{array}$ & $\begin{array}{l}50.75 \pm \\
7.44^{\# \#}\end{array}$ & $\begin{array}{l}52.41 \pm \\
8.95^{\# \#}\end{array}$ & $\begin{array}{l}50.26 \pm \\
10.72^{\# \#}\end{array}$ & $\begin{array}{l}195.83 \\
\pm 29.66\end{array}$ & $48.07 \pm 3.22$ \\
\hline \multirow[t]{2}{*}{$\begin{array}{l}\text { Phosphagen } \\
\text { system (kJ) }\end{array}$} & PYR & $\begin{array}{l}36.15 \\
\pm 6.69\end{array}$ & $\begin{array}{l}40.20 \pm \\
7.37^{\# \#}\end{array}$ & $\begin{array}{l}41.07 \pm \\
5.91^{\# \#}\end{array}$ & $\begin{array}{l}35.85 \pm \\
3.71\end{array}$ & $\begin{array}{l}149.86 \\
\pm 15.27\end{array}$ & $36.57 \pm 2.13$ \\
\hline & PLA & $\begin{array}{l}37.87 \\
\pm 5.64\end{array}$ & $\begin{array}{l}40.16 \pm \\
5.50^{\# \#}\end{array}$ & $\begin{array}{l}41.23 \pm \\
7.04^{\#}\end{array}$ & $\begin{array}{l}34.62 \pm \\
4.71\end{array}$ & $\begin{array}{l}151.59 \\
\pm 16.53\end{array}$ & $37.36 \pm 2.09$ \\
\hline \multirow[t]{2}{*}{$\begin{array}{l}\text { Glycolytic } \\
\text { system (kJ) }\end{array}$} & PYR & $\begin{array}{l}19.43 \\
\pm 5.22\end{array}$ & $\begin{array}{l}13.74 \pm \\
6.87^{\# \#}\end{array}$ & $\begin{array}{l}10.16 \pm \\
7.07^{\# \#}\end{array}$ & $\begin{array}{l}7.64 \pm \\
6.51^{\# \#}\end{array}$ & $\begin{array}{l}57.06 \pm \\
9.66\end{array}$ & $13.96 \pm 2.33$ \\
\hline & PLA & $\begin{array}{l}20.64 \\
\pm 5.70\end{array}$ & $\begin{array}{l}15.11 \pm \\
4.57^{\# \#}\end{array}$ & $\begin{array}{l}11.05 \pm \\
6.94^{\# \#}\end{array}$ & $\begin{array}{l}8.14 \pm \\
7.03^{\# \#}\end{array}$ & $\begin{array}{l}58.84 \pm \\
8.80\end{array}$ & $14.56 \pm 2.15$ \\
\hline
\end{tabular}

\section{RSE performance}

Compared to PLA, pyruvate significantly increased the average $\operatorname{RPP}(p<0.05)$ and $\operatorname{RAP}(p<0.05)$ but not the PD\% ( $p>0.05)$ during RSE (Fig. 2). Compared to sprint 1, $\operatorname{RPP}(p<0.05)$ and $\operatorname{RAP}(p<0.05,0.01)$ decreased, while PD\% $(p<0.05,0.01)$ increased throughout sprints during RSE in both groups. Furthermore, RPP of the first and fifth sprints in PYR were higher than PLA $(p<0.05)$. RAP of first sprint in PYR was higher than PLA $(p<0.05)$. No significant difference of PD\% between PYR and PLA of each sprint during RSE (Table 4). 
Table 4

RPP, RAP and PD\% during RSE for each sprint

\begin{tabular}{|c|c|c|c|c|c|c|c|}
\hline & & Sprint 1 & Sprint 2 & Sprint 3 & Sprint 4 & Sprint 5 & Sprint 6 \\
\hline \multirow[t]{2}{*}{$\begin{array}{l}\text { RPP } \\
(W / k g)\end{array}$} & PYR & $\begin{array}{l}11.52 \pm \\
1.21^{*}\end{array}$ & $\begin{array}{l}11.16 \pm \\
0.64^{\Phi}\end{array}$ & $\begin{array}{l}10.50 \pm \\
0.91^{\Phi}\end{array}$ & $\begin{array}{l}10.00 \pm \\
0.86^{\Phi}\end{array}$ & $\begin{array}{l}10.40 \pm \\
1.47 *\end{array}$ & $\begin{array}{l}10.07 \pm \\
1.38^{\Phi}\end{array}$ \\
\hline & PLA & $\begin{array}{l}10.34 \pm \\
1.06\end{array}$ & $\begin{array}{l}10.27 \pm \\
1.71\end{array}$ & $\begin{array}{l}10.02 \pm \\
0.94\end{array}$ & $9.81 \pm 0.77$ & $\begin{array}{l}9.05 \pm \\
1.16^{\Phi}\end{array}$ & $9.96 \pm 1.36$ \\
\hline \multirow[t]{2}{*}{$\begin{array}{l}\text { RAP } \\
(W / k g)\end{array}$} & PYR & $\begin{array}{l}10.13 \pm \\
1.57\end{array}$ & $\begin{array}{l}10.00 \pm \\
0.84\end{array}$ & $\begin{array}{l}9.25 \pm \\
0.60^{\Phi}\end{array}$ & $\begin{array}{l}8.54 \pm \\
0.88^{\Phi \Phi}\end{array}$ & $\begin{array}{l}8.47 \pm \\
0.80 * \Phi \Phi\end{array}$ & $\begin{array}{l}8.33 \pm \\
1.07^{\Phi \Phi}\end{array}$ \\
\hline & PLA & $\begin{array}{l}9.49 \pm \\
1.21\end{array}$ & $\begin{array}{l}9.40 \pm \\
1.15\end{array}$ & $\begin{array}{l}8.96 \pm \\
0.67\end{array}$ & $\begin{array}{l}8.40 \pm \\
0.64^{\Phi}\end{array}$ & $\begin{array}{l}7.65 \pm \\
1.03^{\Phi}\end{array}$ & $8.15 \pm 0.94^{\Phi}$ \\
\hline \multirow[t]{2}{*}{ PD\% } & PYR & $\begin{array}{l}19.50 \\
(14.08 \\
27.05)\end{array}$ & $\begin{array}{l}16.52 \\
(12.41 \\
25.10)\end{array}$ & $\begin{array}{l}20.71 \\
(19.40 \\
25.82)\end{array}$ & $\begin{array}{l}23.85 \\
(18.36 \\
37.36)^{\Phi}\end{array}$ & $\begin{array}{l}27.37 \\
(20.61 \\
42.81)^{\Phi}\end{array}$ & $\begin{array}{l}36.28 \\
(29.44 \\
40.29)^{\Phi}\end{array}$ \\
\hline & PLA & $\begin{array}{l}21.08 \\
(18.55 \\
23.66)\end{array}$ & $\begin{array}{l}20.30 \\
(14.45 \\
25.77)\end{array}$ & $\begin{array}{l}25.42 \\
(17.29 \\
26.75)\end{array}$ & $\begin{array}{l}28.22 \\
(24.73 \\
34.71)\end{array}$ & $\begin{array}{l}35.1 \\
(23.77 \\
43.54)\end{array}$ & $\begin{array}{l}30.09 \\
(25.75 \\
42.69)\end{array}$ \\
\hline
\end{tabular}

\section{Discussion}

This is the first study examined the effects of 1-week pyruvate supplementation on energy metabolism, metabolic acidosis during HIIE and evaluated RSE performance in well-trained soccer athletes. Enhanced oxidative metabolism can help athletes perform better by eliminating $\mathrm{H}^{+}$intracellularly and increasing $\mathrm{PCr}$ resynthesis. The results showed that pyruvate supplementation enhanced oxidative system contribution during HIIE. Second, pyruvate attenuated acidosis during HIIE and RSE. Third, RPP in the first and fifth sprints, RAP in the fifth sprint, the average RPP and RAP during RSE were significantly increased in PYR. But energy contribution of phosphagen, glycolytic systems during HIIE as well as PD\% of RSE were unaffected by pyruvate intake.

There were little research examining the impact of pyruvate on the energy metabolism of HIIE. We used a non-invasive quantitative approach to estimate metabolism of the three energy systems (oxidative, phosphagen and glycolytic) ${ }^{39,40}$. In this study, the same dose of pyruvate or maltodextrin supplementation in both groups had ruled out caloric influence in energy metabolism. The trends of the three energy systems contributions in the two groups were the same, which were mainly associated with HIIE. Those results were compatible with data from other literature studying HIIE energy metabolism ${ }^{41}$. Furthermore, pyruvate positively augmented the contribution of oxidative energy system in the fourth bout of HIIE. Pyruvate, on the other hand, may bridge the gap between aerobic and anaerobic energy 
supply during HIIE, which contributed to explain its promotion of the oxidative energy system. As previously described, pyruvate ingestion can effectively increase PDH activity, tricarboxylic acid cycle flux and mitochondrial NADH generation, which boosts oxidative energy metabolism 25, 42, 43, 44, 45. However, no effect of pyruvate on total oxidative energy contribution during HIIE was observed in the current study.

In terms of the obtained results, after $\mathrm{HIIE}$, blood $\mathrm{pH}, \mathrm{HCO}_{3}{ }^{-}$and $\mathrm{BE}$ all decreased, while blood lactate increased, indicating that 4 bouts of $110 \%$ high-intensity exercise in this study induced metabolic acidosis, which is consistent with previous research ${ }^{41}$. Moreover, we found that pyruvate supplemented for 1-week improves the blood acid-base status at rest. Previous studies of acute pyruvate supplementation have found this effect ${ }^{29,30}$. Among the main findings of this study, it is suggested that pyruvate supplemented for 1-week increased the alkaline reservation and buffered HIIE induced metabolic acidosis. Following previous work, pyruvate eliminates $\mathrm{H}^{+}$intracellularly and reduces the efflux of $\mathrm{H}^{+}$into blood ${ }^{46}$. The amount of $\mathrm{HCO}_{3}{ }^{-}$involved in $\mathrm{H}^{+}$neutralization was decreased, resulting in a higher level of $\mathrm{HCO}_{3}{ }^{-}$in the blood ${ }^{47}$. However, acute pyruvate supplementation has not been shown to buffer metabolic acidosis induced by 6 -min of $90 \% \mathrm{VO}_{2 \max }$ intensity exercise ${ }^{30}$. It is possible that, since the acute pyruvate supplement appeared to have little effect on energy metabolism. In this research, the supplementation time was extended, making the effect more accessible.

In addition, inconsistent with previous research that pyruvate supplementation promoted blood lactate after a 6-min of $90 \% \mathrm{VO}_{2 \max }$ intensity exercise ${ }^{30}$, our study showed no significant change of blood lactate during HIIE. One explanation was that pyruvate eliminated $\mathrm{H}^{+}$intracellularly and decreased the muscle-to-blood $\mathrm{H}^{+}$gradient, thereby reducing lactate output into blood ${ }^{46,48}$. In addition, pyruvate promoted oxidative energy metabolism and consumed more lactate during the interval period of HIIE 49 . Furthermore, pyruvate improved oxidative metabolism and reduced the dependence on anaerobic energy supply, thereby reducing the production of lactate during HIIE.

The potential for preservation of RPP and RAP always be of interest to athletes where repeated maximal powerful performance is required ${ }^{6}$. RSE test is regarded as a valid indirect measure of RPP and RAP ${ }^{50}$. At the beginning of RSE, PCr accounted for a larger proportion of anaerobic energy contribution ${ }^{51}$, but the resynthesis about half the depletion restored in $30 \mathrm{~s}^{52}$. As a result, $\mathrm{PCr}$ utilization will be the dominant anaerobic ATP contribution process during RSE ${ }^{51,52}$. Furthermore, RSE was also accompanied by $\mathrm{H}^{+}$ accumulation generated by anaerobic energy, which could impair muscle contraction and exercise efficiency ${ }^{15}$. Our study is in line with other studies, which showed RPP, RAP declined and PD\% increased throughout each sprint during RSE, indicating a decrease in exercise efficiency ${ }^{53,54}$. According to current study, pyruvate enhanced the ability of oxidative system and may benefited to resynthesis PCr, as well as attenuated the metabolic acidosis induced by exercise, consequently significantly improved RSE performance.

\section{LIMITATION}


The participants were college soccer athletes. Due to training commitments, collecting muscle tissue was challenging to achieve. The present study only evaluated acid-base response in venous blood, but the regulation of pyruvate in skeletal muscle cells could not be effectively evaluated.

\section{Conclusions}

Acute pyruvate supplementation may increase alkaline reservation in the resting state, but may not prevent acidosis induced by high-intensity exercise. Supplementing of $0.1 \mathrm{~g} / \mathrm{kg} / \mathrm{d}$ for 1 -week can significantly attenuate the acidosis and regulate energy metabolism during HIIE, which are beneficial to the performance of RSE. In addition, this study provides new insights into the intracellular metabolism of skeletal muscle in response to pyruvate supplementation.

\section{Abbreviations}

HIIE: High-intensity interval exercise; RSE: Repeated sprint exercise; $\mathrm{HCO}_{3}{ }^{-}$: Bicarbonate; $\mathrm{BE}$ : Base excess; PYR: Pyruvate group; PLA: Placebo group; ATP-CP: Phosphagen; $\mathrm{H}^{+}$: Hydrogen ion; PDK, Pyruvate dehydrogenase kinase; PDH: Pyruvate dehydrogenase; $p K a$ : Dissociation constant; $W_{\text {max }}$ : Maximal power output; $\mathrm{RO}_{2}$ : Resting oxygen uptake test; GXT: Graded cycling exercise test; RPE: Rate of perceived exertion; HR: Heart rate; RPP: Relative peak power; RAP: Relative average power; PD\%: Power drop; EPOC fast: Fast component of excess post-exercise oxygen consumption

\section{Declarations}

\section{Ethics approval and consent to participate}

The research proposal was approved by the Internal Review Board of Beijing Sport University (BSU IRB). All participants signed a written informed consent prior to participating in this study (2020057H).

\section{Consent for Publication}

Not applicable, no individual person's data was presented.

\section{Availability of data and material}

The datasets generated and/or analyzed as part of the current study are not publicly available due to confidentiality agreements with subjects. However, they can be made available solely for the purpose of review and not for the purpose of publication from the corresponding author upon reasonable request.

\section{Competing interests}


No authors declare competing interests.

\section{Funding}

Funding was provided by the Herbalife Winter Sports Development Fund and the National Key R\&D Program of China (2018YFC2000600).

\section{Authors Contributions}

YP was responsible for the study design, data collection, data interpretation, writing and revision of the manuscript, under the direction of JQ. MYW was in charge of participant recruitment and management. $D L, L F, R R G$ assisted in the completion of the manuscript. The authors declare no conflict of interests with the current publication, and all authors approved the final version of the manuscript.

\section{Acknowledgments}

The authors would like to sincerely thank the participants for volunteered participating in this study.

\section{References}

1. Engel FA, Ackermann A, Chtourou H, et al. High-Intensity Interval Training Performed by Young Athletes: A Systematic Review and Meta-Analysis [J]. Front Physiol, 2018, 9: 1012.

2. Morrison MA, Spriet LL, Dyck DJ. Pyruvate ingestion for 7 days does not improve aerobic performance in well-trained individuals [J]. J Appl Physiol (1985), 2000, 89(2): 549-56.

3. Robergs RA, Ghiasvand F, Parker D. Biochemistry of exercise-induced metabolic acidosis [J]. Am J Physiol Regul Integr Comp Physiol, 2004, 287(3): R502-16.

4. Juel C, Klarskov C, Nielsen JJ, et al. Effect of high-intensity intermittent training on lactate and $\mathrm{H}+$ release from human skeletal muscle [J]. Am J Physiol Endocrinol Metab, 2004, 286(2): E245-51.

5. Bendiksen M, Bischoff R, Randers MB, et al. The Copenhagen Soccer Test: physiological response and fatigue development [J]. Med Sci Sports Exerc, 2012, 44(8): 1595-603.

6. Girard O, Mendez-Villanueva A, Bishop D. Repeated-sprint ability - part I: factors contributing to fatigue [J]. Sports Med, 2011, 41(8): 673-94.

7. Robergs R, Kennedy D. Metabolic acidosis and fatigue: Where to from here? [J]. Regulation of Fatigue in Exercise, 2011: 41-61.

8. Bishop DJ, Thomas C, Moore-Morris T, et al. Sodium bicarbonate ingestion prior to training improves mitochondrial adaptations in rats [J]. Am J Physiol Endocrinol Metab, 2010, 299(2): E225-33.

9. Kamel KS, Oh MS, Halperin ML. L-lactic acidosis: pathophysiology, classification, and causes; emphasis on biochemical and metabolic basis [J]. Kidney Int, 2020, 97(1): 75-88. 
10. Lühker O, Berger MM, Pohlmann A, et al. Changes in acid-base and ion balance during exercise in normoxia and normobaric hypoxia [J]. Eur J Appl Physiol, 2017, 117(11): 2251-61.

11. Debold EP, Beck SE, Warshaw DM. Effect of low pH on single skeletal muscle myosin mechanics and kinetics [J]. Am J Physiol Cell Physiol, 2008, 295(1): C173-9.

12. Spriet LL, Lindinger MI, McKelvie RS, et al. Muscle glycogenolysis and $\mathrm{H}+$ concentration during maximal intermittent cycling [J]. J Appl Physiol (1985), 1989, 66(1): 8-13.

13. Overgaard K, Højfeldt GW, Nielsen OB. Effects of acidification and increased extracellular potassium on dynamic muscle contractions in isolated rat muscles [J]. J Physiol, 2010, 588(Pt 24): 5065-76.

14. Westerblad H, Allen DG. Myoplasmic free Mg2+ concentration during repetitive stimulation of single fibres from mouse skeletal muscle [J]. J Physiol, 1992, 453: 413-34.

15. Maclntosh BR, Holash RJ, Renaud JM. Skeletal muscle fatigue-regulation of excitation-contraction coupling to avoid metabolic catastrophe [J]. J Cell Sci, 2012, 125(Pt 9): 2105-14.

16. Carling C, Bloomfield J, Nelsen L, et al. The role of motion analysis in elite soccer: contemporary performance measurement techniques and work rate data [J]. Sports Med, 2008, 38(10): 839-62.

17. Jubrias SA, Crowther GJ, Shankland EG, et al. Acidosis inhibits oxidative phosphorylation in contracting human skeletal muscle in vivo [J]. J Physiol, 2003, 553(Pt 2): 589-99.

18. Hadzic M, Eckstein ML, Schugardt M. The Impact of Sodium Bicarbonate on Performance in Response to Exercise Duration in Athletes: A Systematic Review [J]. J Sports Sci Med, 2019, 18(2): 271-81.

19. Kumstát M, Hlinský T, Struhár I, et al. Does Sodium Citrate Cause the Same Ergogenic Effect As Sodium Bicarbonate on Swimming Performance? [J]. J Hum Kinet, 2018, 65: 89-98.

20. Morris DM, Shafer RS, Fairbrother KR, et al. Effects of lactate consumption on blood bicarbonate levels and performance during high-intensity exercise [J]. Int J Sport Nutr Exerc Metab, 2011, 21(4): 311-7.

21. Halestrap AP. The monocarboxylate transporter family-Structure and functional characterization [J]. IUBMB Life, 2012, 64(1): 1-9.

22. Yang J, Zhao JX, Wang Y, et al. Effects of sodium pyruvate on ameliorating metabolic acidosis [J]. Artif Cells Nanomed Biotechnol, 2016, 44(1): 48-55.

23. Hasenfuss G, Maier LS, Hermann HP, et al. Influence of pyruvate on contractile performance and $\mathrm{Ca}(2+)$ cycling in isolated failing human myocardium [J]. Circulation, 2002, 105(2): 194-9.

24. Kukimoto-Niino M, Tokmakov A, Terada T, et al. Inhibitor-bound structures of human pyruvate dehydrogenase kinase 4 [J]. Acta Crystallogr D Biol Crystallogr, 2011, 67(Pt 9): 763-73.

25. Jaimes R, 3rd, Kuzmiak-Glancy S, Brooks DM, et al. Functional response of the isolated, perfused normoxic heart to pyruvate dehydrogenase activation by dichloroacetate and pyruvate [J]. Pflugers Arch, 2016, 468(1): 131-42.

26. Schroeder MA, Cochlin LE, Heather LC, et al. In vivo assessment of pyruvate dehydrogenase flux in the heart using hyperpolarized carbon-13 magnetic resonance [J]. Proc Natl Acad Sci U S A, 2008, 
105(33): 12051-6.

27. Sharma G, Wu CY, Wynn RM, et al. Real-time hyperpolarized (13)C magnetic resonance detects increased pyruvate oxidation in pyruvate dehydrogenase kinase 2/4-double knockout mouse livers [J]. Sci Rep, 2019, 9(1): 16480.

28. Flaherty DC, Hoxha B, Sun J, et al. Pyruvate-fortified fluid resuscitation improves hemodynamic stability while suppressing systemic inflammation and myocardial oxidative stress after hemorrhagic shock [J]. Mil Med, 2010, 175(3): 166-72.

29. Olek RA, Luszczyk M, Kujach $S$, et al. Single pyruvate intake induces blood alkalization and modification of resting metabolism in humans [J]. Nutrition, 2015, 31(3): 466-74.

30. Robert 0 , Kujach S, Wnuk D, et al. Single sodium pyruvate ingestion modifies blood Acid-base status and post-exercise lactate concentration in humans [J]. Nutrients, 2014, 6(5): 1981-92.

31. Jacobs RA, Flück D, Bonne TC, et al. Improvements in exercise performance with high-intensity interval training coincide with an increase in skeletal muscle mitochondrial content and function [J]. J Appl Physiol (1985), 2013, 115(6): 785-93.

32. Wang J, Qiu J, Yi L, et al. Effect of sodium bicarbonate ingestion during 6 weeks of HIIT on anaerobic performance of college students [J]. J Int Soc Sports Nutr, 2019, 16(1): 18.

33. Dantas JL, Pereira G, Nakamura FY. Five-Kilometers Time Trial: Preliminary Validation of a Short Test for Cycling Performance Evaluation [J]. Asian J Sports Med, 2015, 6(3): e23802.

34. Borg GA. Psychophysical bases of perceived exertion [J]. Med Sci Sports Exerc, 1982, 14(5): 377-81.

35. Olek RA, Sylwester K, Damian W, et al. Single sodium pyruvate ingestion modifies blood acid-base status and post-exercise lactate concentration in humans [J]. Nutrients, 2014, 6(5): 1981-92.

36. Camps SG, Wang NX, Tan WS, et al. Estimation of basal metabolic rate in Chinese: are the current prediction equations applicable? [J]. Nutr J, 2016, 15(1): 79.

37. Bar-Or O. The Wingate anaerobic test. An update on methodology, reliability and validity [J]. Sports Med, 1987, 4(6): 381-94.

38. Monroe DC, GIST NH, FREESE EC, et al. Effects of Sprint Interval Cycling on Fatigue, Energy, and Cerebral Oxygenation [J]. Med Sci Sports Exerc, 48(4): 615-24.

39. di Prampero PE, Ferretti G. The energetics of anaerobic muscle metabolism: a reappraisal of older and recent concepts [J]. Respir Physiol, 1999, 118(2-3): 103-15.

40. Ozyener F, Rossiter HB, Ward SA, et al. Influence of exercise intensity on the on- and off-transient kinetics of pulmonary oxygen uptake in humans [J]. J Physiol, 2001, 533(Pt 3): 891-902.

41. da Silva RP, de Oliveira LF, Saunders B, et al. Effects of $\beta$-alanine and sodium bicarbonate supplementation on the estimated energy system contribution during high-intensity intermittent exercise [J]. Amino Acids, 2019, 51(1): 83-96.

42. Scholz TD, Laughlin MR, Balaban RS, et al. Effect of substrate on mitochondrial NADH, cytosolic redox state, and phosphorylated compounds in isolated hearts [J]. Am J Physiol, 1995, 268(1 Pt 2): H82-91. 
43. Bünger R, Mallet RT, Hartman DA. Pyruvate-enhanced phosphorylation potential and inotropism in normoxic and postischemic isolated working heart. Near-complete prevention of reperfusion contractile failure [J]. Eur J Biochem, 1989, 180(1): 221-33.

44. Kang YH, Mallet RT, Bünger R. Coronary autoregulation and purine release in normoxic heart at various cytoplasmic phosphorylation potentials: disparate effects of adenosine [J]. Pflugers Arch, 1992, 421(2-3): 188-99.

45. Laughlin MR, Taylor J, Chesnick AS, et al. Pyruvate and lactate metabolism in the in vivo dog heart [J]. Am J Physiol, 1993, 264(6 Pt 2): H2068-79.

46. Aoi W, Marunaka Y. Importance of pH homeostasis in metabolic health and diseases: crucial role of membrane proton transport [J]. Biomed Res Int, 2014, 2014: 598986.

47. Jones RL, Stellingwerff T, Artioli GG, et al. Dose-Response of Sodium Bicarbonate Ingestion Highlights Individuality in Time Course of Blood Analyte Responses [J]. Int J Sport Nutr Exerc Metab, 2016, 26(5): 445-53.

48. Brooks GA. The Science and Translation of Lactate Shuttle Theory [J]. Cell Metab, 2018, 27(4): 75785.

49. Kane DA. Lactate oxidation at the mitochondria: a lactate-malate-aspartate shuttle at work [J]. Front Neurosci, 2014, 8: 366.

50. Driss $T$, Vandewalle $H$. The measurement of maximal (anaerobic) power output on a cycle ergometer: a critical review [J]. Biomed Res Int, 2013, 2013: 589361.

51. Gaitanos GC, Williams C, Boobis LH, et al. Human muscle metabolism during intermittent maximal exercise [J]. J Appl Physiol (1985), 1993, 75(2): 712-9.

52. Harris RC, Edwards RHT, Hultman E, et al. The time course of phosphorylcreatine resynthesis during recovery of the quadriceps muscle in man [J]. Pflügers Archiv, 1976, 367(2): 137-42.

53. Crisafulli DL, Buddhadev HH, Brilla LR, et al. Creatine-electrolyte supplementation improves repeated sprint cycling performance: A double blind randomized control study [J]. J Int Soc Sports Nutr, 2018, 15: 21.

54. Smith KJ, Billaut F. Tissue oxygenation in men and women during repeated-sprint exercise [J]. Int J Sports Physiol Perform, 2012, 7(1): 59-67.

\section{Figures}




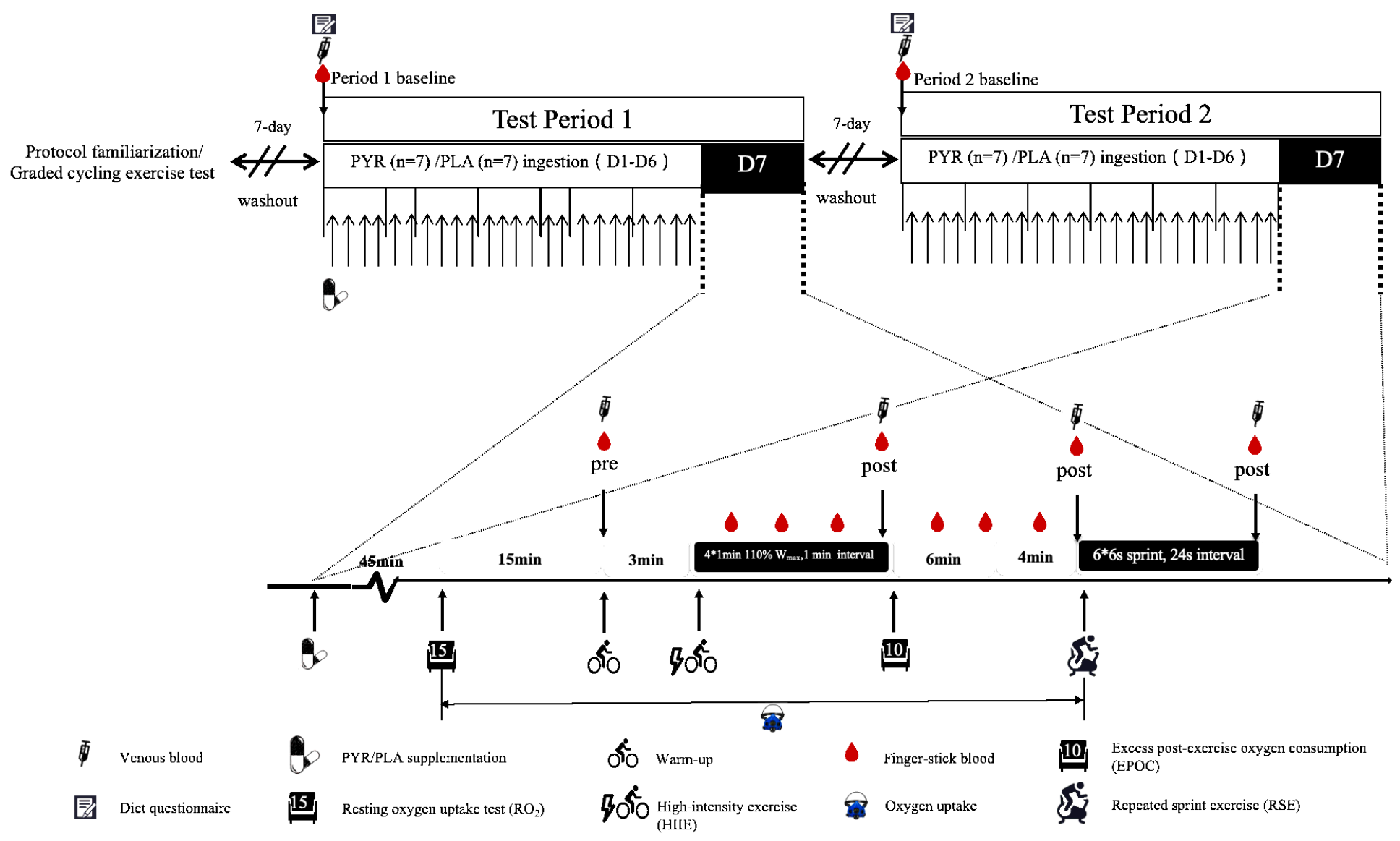

Figure 1

Supplementation and exercise test timeline 


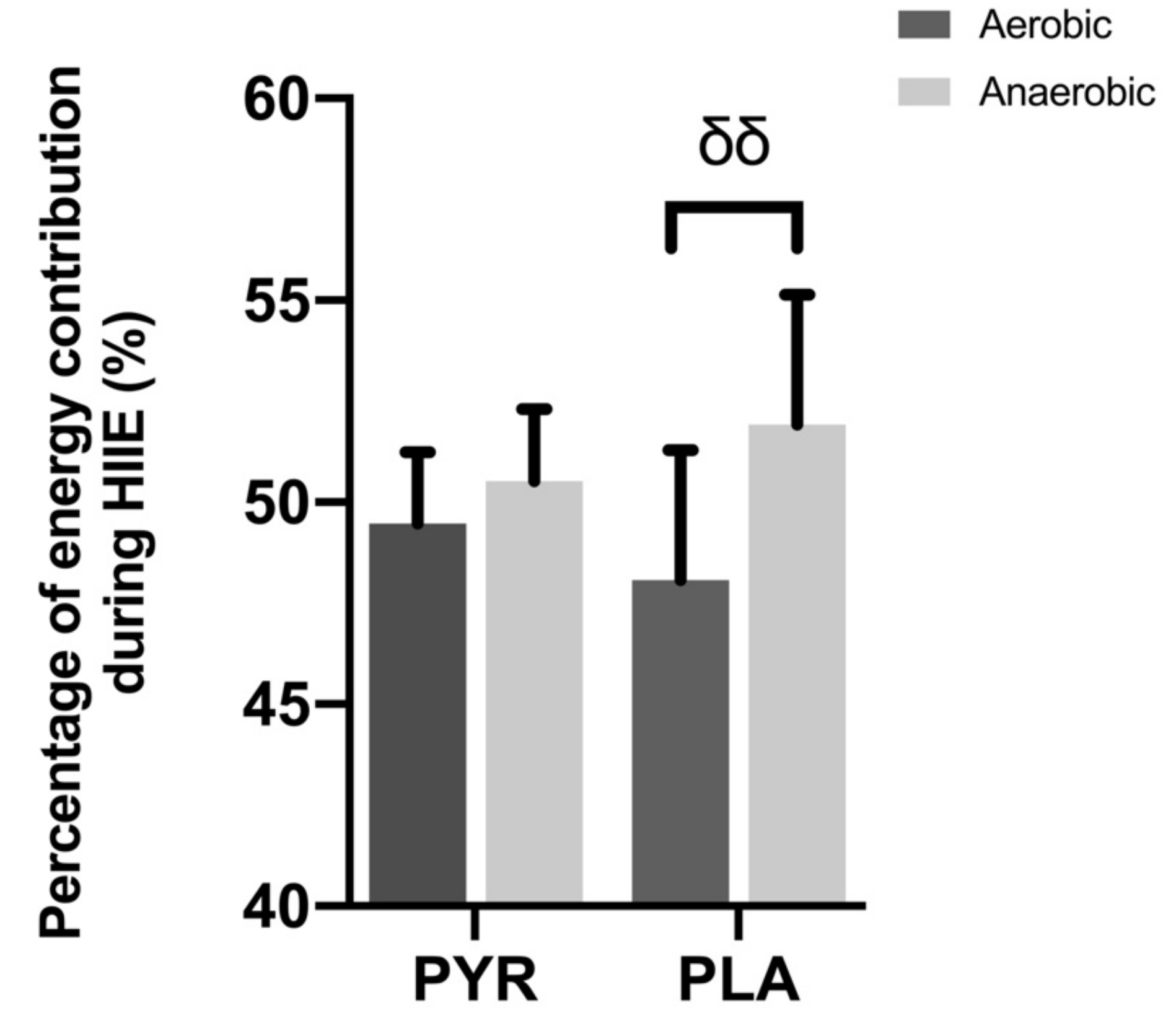

Figure 2

The percentage of aeroibic and anaerobic energy contribution during HIIE (\%). Values are mean \pm SD. The ratio of aerobic energy contribution: (aerbic energy/ total energy) *100; The ratio of anaerobic energy contribution: ((phosphagen energy + glycolytic energy)/ total energy) $* 100 . \delta \delta$ Indicates significant difference between aerobic and anaerobic energy contribution $(p<0.01)$ 
a)

b)
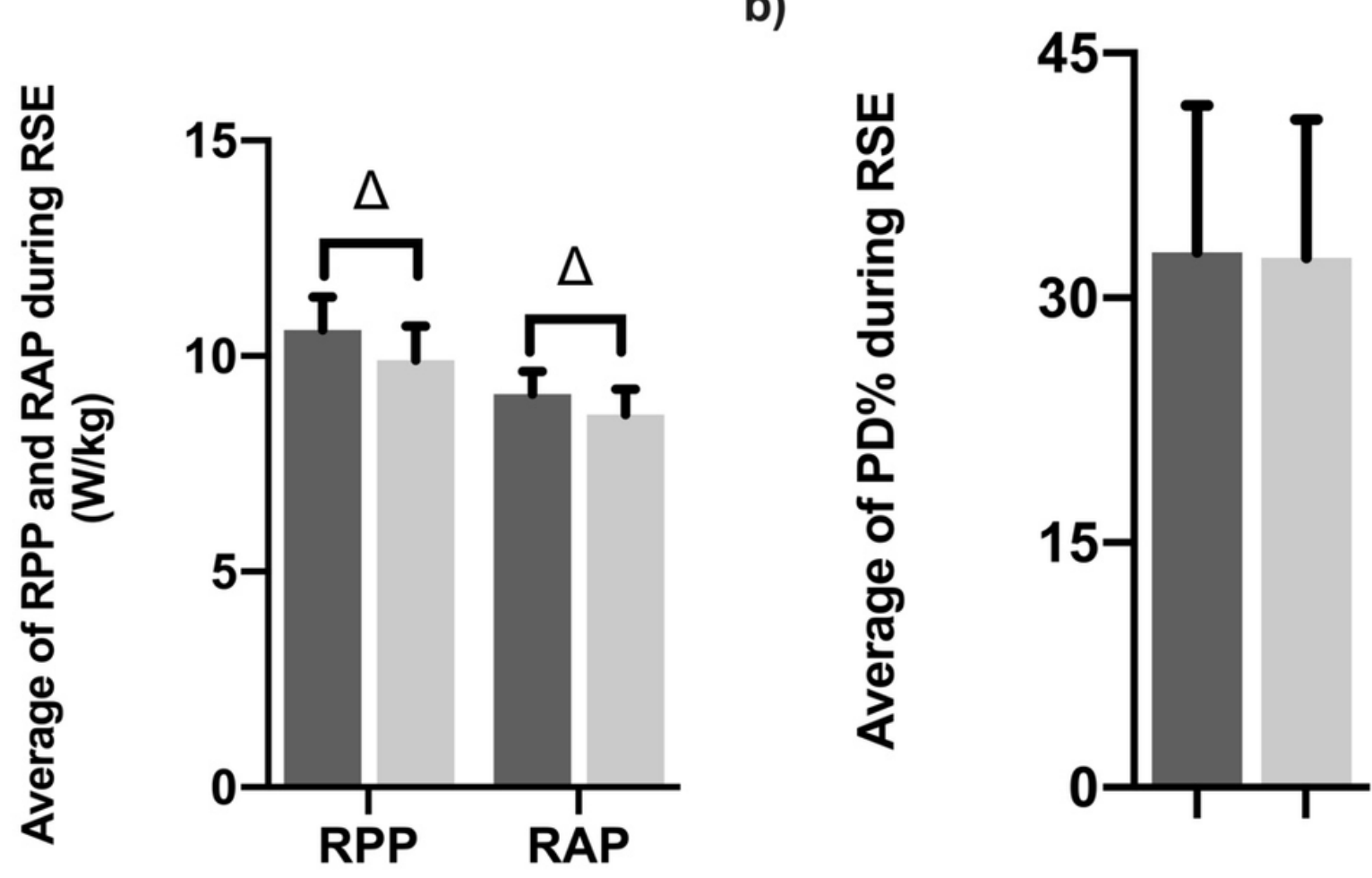

Figure 3

Avarege RPP, RAP (a) and PD\% (b) during RSE. Values are mean \pm SD. $\Delta$ Indicates a significant difference between PYR and PLA $(p<0.05)$ 